\title{
Comunicação, opinião pública e os impactos da revolução digital na era da pós-verdade e fake news
}

Communication, public opinion and the impacts of the digital revolution in the era of post-truth and fake news

Comunicación, opinión pública y los impactos de la revolución digital em la era de la posverdad y de la desinformación

Luiz Alberto de Farias

Livre Docente e Doutor em Comunicação e Cultura pela Universidade de São Paulo (USP).

Professor Associado da Escola de Comunicações e Artes da USP (ECA-USP).

Professor Titular da Universidade Metodista de São Paulo.

E-mail: lafarias@usp.br

Ivelise Cardoso

- Mestra em Ciências da Comunicação pela Escola de Comunicações e Artes da Universidade de São Paulo (ECA/USP).

- $\quad$ MBA em Administração pela Fundação Instituto de Administração (FIA).

- $\quad$ Pós-graduada em Comunicação e Marketing pela Escola Superior de Propaganda e Marketing de São Paulo (ESPM/SP).

- $\quad$ Graduada em Relações Públicas pela Faculdade Cásper Líbero.

- E-mail:ivecardoso@hotmail.com

\section{Paulo Roberto Nassar de Oliveira}

- Diretor-presidente da Associação Brasileira de Comunicação Empresarial (Aberje).

- $\quad$ Professor titular da ECA-USP.

- Doutor e mestre pela ECA-USP.

- E-mail: paulonassar@usp.br 


\section{RESUMO}

0 artigo reflete sobre a propagação da pós-verdade e influência das notícias falsas, disseminadas por algoritmos e redes sociais, e tidas como fonte primária de informação capaz de criar realidades paralelas, incidir sobre tomadas de decisões ou consolidar tendências da sociedade atual. Os meios de comunicação e as autoridades públicas demonstram preocupação com relação à contenção da dissipação do fenômeno pelo mundo, contudo, à frente disto, a tecnologia evolui como aliada das fakes news.

\section{PALAVRAS-CHAVE: PÓS-VERDADE • FAKE NEWS•REDES SOCIAIS • OPINIÃO PÚBLICA・DESINFORMAÇÃO.}

\section{ABSTRACT}

The article reflects on the spread of the post-truth and the influence of fake news, disseminated by algorithms and social media, and considered as the primary source of information capable of creating parallel realities, influencing decision-making or consolidating trends in today's society. The media and public authorities are concerned about containing the dissipation of the phenomenon around the world, however, ahead of this, technology evolves as an ally of fakes news.

\section{KEYWORDS: POST-TRUTH • FAKE NEWS • SOCIAL MEDIA • PUBLIC OPINION・MISINFORMATION.}

\section{RESUMEN}

El artículo reflexiona sobre la difusión de la posverdad y la influencia de las noticias falsas, difundidas por algoritmos y redes sociales, y consideradas una fuente primaria de información capaz de crear realidades paralelas, de influir en la toma de decisiones o de consolidar tendencias en la sociedad actual. Los medios de comunicación y las autoridades públicas están preocupados por contener la disipación del fenómeno en todo el mundo, sin embargo, la tecnología evoluciona como aliada de las fake news. 
A contemporaneidade trouxe uma série de mudanças ao universo das organizações, com novos desafios impactados por tecnologias que se renovam de modo incrivelmente rápido, como mudanças de comportamento dos diversos públicos que se relacionam com essas mesmas organizações, sejam elas do primeiro, segundo ou terceiro setores. 0 conjunto de enunciados e de enunciações deve ser repensado a partir da ótica da comunicação. A novos cenários estão sujeitos todos os que vivenciam o ambiente organizacional e são consumidores e produtores de informação. Sujeitos ainda a ações de embaixadores e de detratores de imagens e reputações. E essas reputações afetam campos concretos e simbólicos, ambientes institucionais e mercadológicos.

Este artigo terá como pano de fundo a reflexão sobre o impacto que as tecnologias, representadas pelas mídias e redes sociais digitais, têm sobre a construção de para-realidades com o deslocamento da verdade, isso motivado por cenários de pós-verdade e fake news. Trata-se, portanto, de colocar em debate conceitos e teorias que buscam explicar os movimentos que têm ganhado espaço em diversos países, notadamente explícitos no campo político, mas que apresentam relação direta com o ambiente de todas as organizações, gerando desdobramentos na comunicação organizacional e nas relações públicas.

Assim, um dos grandes ataques ao ambiente organizacional e às relações deste com os diversos públicos é a chamada pósverdade, que reflete uma espécie de modalidade pós-moderna, um estado distorcido de consciência, no qual os estereótipos perdem completamente a conexão com as imagens reais. As plataformas digitais não apenas introduziram novas práticas de leitura, como também mudaram os processos interpretativos que os indivíduos normalmente trazem ao ler notícias e artigos.

Segundo Angeluci, Soares e Freitas (2019), com o passar dos dias tem sido cada vez mais perceptível que os jovens deste século têm se tornado mais midiatizados e conectados à Internet, principalmente em acessos realizados pelos seus aparelhos celulares. Conforme dito por Sodré (2002), a midiatização tem a ver com a propagação das tecnologias na vida social, que acaba sendo um processo muito importante na vida desse século e das pessoas envolvidas. E foi com o surgimento das redes sociais que isso aconteceu de maneira mais rápida, podendo ser feita de qualquer dispositivo móvel, qualquer lugar e a qualquer momento.

Nas mídias sociais, os indivíduos são incentivados a "curtir", compartilhar e comentar textos digitais, uma interação com forte estímulo e condicionamento. No processo, esses textos acumulam credibilidade e valor para aqueles que os divulgam, como 0 aumento das conexões sociais e o moral pessoal.

A cultura de compartilhar exige, muitas vezes, um maior esforço por parte do espectador para recuperar e interpretar o significado implícito e intertextual vinculado a textos compartilhados. Como tal, a interpretação leva a um senso de recompensa em que o espectador se torna um insider ou "parte de uma elite". (Adami, 2012, p.132, tradução nossa)

A arquitetura, os algoritmos e os efeitos de rede da plataforma mudaram a forma como as notícias são criadas e divulgadas. Embora as mídias sociais tenham facilitado e diversificado processos de difusão do conhecimento, elas oferecem um terreno fértil para a criação e propagação de desinformação (Tambuscio etal., 2015). Uma quantidade substancial de conteúdo de mídia social consiste em informações de crowdsourcing que ignoram o processo significativo de verificação de fatos, julgamento editorial ou gatekeeping.

Desde as primeiras descrições retóricas das comunidades virtuais, a Web nos permitiu conhecer e interagir facilmente com pessoas que pensam como nós. No entanto, hoje vivemos em um mundo online onde homofilia não é o resultado de nossas próprias escolhas, mas o objetivo de algoritmos que filtram tudo o que não gostamos, sem perceber isso. Esta quantidade prodigiosa de pessoal informação e o enorme número de vestígios que deixamos assim também é usado pelos algoritmos que moldam o mundo ao nosso gosto. (Paccagnella, 2018, p.10, tradução nossa) 
A quantidade de plataformas disponíveis em que o indivíduo pode se expressar aumentou consideravelmente ao longo dos últimos anos. Qualquer pessoa pode abrir um site, um blog ou um perfil em quaisquer plataformas que quiser. 0 verbo, a imagem e o som, quase sempre juntos, são agora criados, compartilhados, aceitos. Comentados ou atacados e defendidos de numerosas maneiras, em diversas plataformas, por milhões de pessoas. (Santaella, 2018).

As novas possibilidades relacionais da sociedade em rede (Castells, 2009), potencializadas pelas novas mídias digitais, resultam em um contexto em que o poder da informação e o compromisso com a verdade estão descentralizados. Ao mesmo tempo em que as pessoas possuem uma obsessão pelas novidades e notícias, elas consomem vorazmente mensagens superficiais e passageiras. Paralelamente, buscam formar uma opinião particular sobre o mundo sendo que, simultaneamente, são enfraquecidas pelas capacidades de fazer conexões significativas entre os acontecimentos - efêmeros e esquecíveis.

Alvin Toffler (1973) foi um dos mais celebrados autores que se dedicaram a antecipar as transformações a que a vida das pessoas e das instituições foi sujeita nas últimas décadas do século XX com a ascensão da tecnologia digital. 0 guru da era pós-industrial foi um dos precursores a escrever sobre sobrecarga de informação - information overload-antes mesmo da propagação das mídias digitais, e descreveu "sensação de desorientação vertiginosa provocada pela chegada prematura do futuro" na "Era da Informação" (termo que ele cunhou).

Toffler (1973) alertou para as perturbações que adviriam de "demasiada mudança em um curto período de tempo", e anunciou os perigos e a sensação geral de ansiedade que as pessoas iriam sentir perante a incapacidade de se adaptarem à sucessão rápida de avanços tecnológicos e à quantidade avassaladora de informação que não dá tréguas a quem tenta processá-la.

O autor já alertava que o crescimento das tecnologias aumentaria a produção de informações tão rápida e em volumes tão grandes que as pessoas teriam dificuldades em processar e absorver grandes cargas de informação, em discernir suas relevâncias e em dar algum sentido a elas, analisando-as e transformando-as em algo realmente útil para suas vidas, ou seja, converter informação em conhecimento e em conceito.

O excesso de informação disponível pelos diferentes meios midiáticos faz com que as pessoas tenham grandes dificuldades em concentrar-se no que realmente é importante, prejudicando seu poder de avaliar o conteúdo das notícias. Os cérebros possuem capacidade limitada de atenção e estão sofrendo com tanta informação (Naish, 2009).

Diante do grande volume de informações disponível todos os dias nas redes sociais e da ansiedade que 0 nowism provoca para consumi-las, é relevante enfatizar os riscos que se corre ao não usar filtros para selecionar o que realmente merece ser levado em consideração. 0 mesmo nowism que prova a busca incessante por informações factuais é um dos responsáveis pelo grande número de inverdades que obtém notoriedade. Os veículos de comunicação temem ganhar o status de desatualizados e, em muitas situações veiculam informações baseados apenas em depoimentos postados nas redes sociais, desconsiderando a averiguação in loco da situação descrita pelo autor da mensagem. Mesmo que corrijam a informação na sequência, ao descobrir o erro, maculam a relação com o público. (Baldessar; Zandomênico, 2014, p.101-102)

0 momento atual é destacado pela forte influência da tecnologia digital, que influencia a redução do tempo entre 0 acontecimento e a veiculação dele. As métricas de postagem do YouTube, por exemplo, indicam que diariamente os usuários do canal postam 7 mil horas de conteúdo noticiosos, não mediado pelos veículos de comunicação.

Como posto por Marlet e Batista (2014), é inegável a influência que a mídia exerce nas relações sociais e culturais humanas. Para tanto, devemos pensá-la como um processo de mediação, ou seja, como uma constante circulação de significados entre enunciadores e enunciatários/receptores. Ela envolve produtores e consumidores de mídia numa atividade contínua de 
engajamento e desengajamento com significados que possuem sua fonte ou seu foco nos textos mediados, mas que dilatam a experiência e são avaliados à luz de diversas maneiras (Silverstone, 2011).

Em "Notícias falsas e liberdade de expressão e informação: o controle do conteúdo da informação na rede", o autor comenta que os resultados da eleição presidencial nos Estados Unidos e a votação no Reino Unido para deixar a União Européia (Brexit) levantaram questões sobre a influência das notícias falsas originadas em páginas criadas em sites e rapidamente disseminadas por meio das redes sociais.

Como posto por Pauner Chulvi (2017), refletem sobre os problemas decorrentes do controle do conteúdo da internet e, mais especificamente, qual deve ser a resposta legítima à desinformação, quais são os riscos derivados da imposição de filtragem e rotulagem de informações, a possibilidade de criar um sistema de censura privada que compromete o pluralismo da rede ou o perigo de arbitrariedade na construção do algoritmo de filtragem e sua eficácia no exercício da liberdade de expressão em diversos contextos (como ironia ou humor), entre outras questões.

Segundo Matsa e Mitchell (2014), 78\% dos usuários veem notícias quando estão usando o Facebook por outros motivos. Enquanto apenas 34\% dos usuários assinam uma fonte de mídia de notícias nas redes sociais. Encontrar notícias por meio da esfera social, e não da esfera de notícias e informações, significa que o artigo não é lido no contexto, dando às pessoas menos oportunidade de comparar a estrutura, o estilo e a voz a outros artigos de notícias. Relacionado a isso, a descoberta de notícias e informações não é mais uma busca individual, mas sim um empreendimento social (Nikolov et al., 2015).

Isso não apenas altera a forma como as pessoas descobrem notícias e informações, mas também sua disposição fundamental para se engajar nesses artigos. Normalmente, os usuários não sentem a necessidade de ser críticos neste espaço, visto que uma plataforma de mídia social como o Facebook é um site para compartilhar notícias e informações com os amigos. "O ecossistema de notícias mudou mais dramaticamente nos últimos cinco anos", escreveu Katherine Vinner (2015), "do que talvez em qualquer época nos últimos 500. 0 futuro da publicação está sendo colocado nas mãos de poucos, que agora controlam o destino dos muitos".

As editoras de notícias perderam o controle sobre a distribuição de seu jornalismo, que para muitos leitores agora é "filtrado por meio de algoritmos e plataformas que são opacas e imprevisíveis". Isso significa que as empresas de mídia social se tornaram incrivelmente poderosas na determinação do que lemos - e enormemente lucrativas com a monetização do trabalho de outras pessoas. Como Vinner (2015) observa, "há uma concentração muito maior de poder nesse aspecto do que jamais houve no passado".

Matsa e Mitchell (2014) argumentam que quanto mais uma pessoa confia em conteúdo personalizado, mais provável é que tenha premissas preconceituosas sobre as notícias em seu feed de mídia social. De fato, quando um evento é percebido como altamente polarizador, a tendência é que os indivíduos prefiram poucas fontes online que serviriam para reforçar sua crença anterior sobre uma pessoa ou evento (Koutra; Bennett; Horvitz, 2014).

Quando Eli Pariser (2015) cunhou o termo "bolha de filtro", em 2011, ele estava falando sobre como a web personalizada e em particular a função de busca do Google - demonstra estarmos menos propensos a sermos expostos a informações que nos desafiam ou ampliam nossa visão de mundo, e menos propensos a encontrar fatos que refutem informações falsas que outras pessoas compartilharam. 0 argumento de Pariser (2015), na época, era que as plataformas de mídia social deveriam garantir que "seus algoritmos priorizem visualizações e notícias contrárias que são importantes, não apenas as mais populares ou mais autovalidadas". Mas, em menos de cinco anos, graças ao poder de algumas plataformas sociais, a bolha de filtros descrita por Pariser se tornou muito mais extrema. 
Sobre a pós-verdade, Dillet (2017) pontua que as fakes news sempre existiram, mas se tornaram proeminentes na atual era da mídia social. Nesse sentido, argumenta que:

A pós-verdade é uma palavra da moda, um sintoma dessa era digital: não transgredimos ou transcendemos a verdade; em vez disso, a verdade é maleável, é construída em graus variados do valor e do sistema de crenças de um indivíduo. Não são mais as instituições e os jornais que manipulam as notícias, mas sim qualquer indivíduo privado com uma conta no Facebook ou no Twitter. (Dillet, 2017, p.518, tradução nossa)

A desinformação na mídia digital certamente não é um fenômeno novo (Floridi, 1996) e argumenta-se que, no contexto da mídia digital, como em todos os meios comerciais, os provedores de conteúdo geram receita de propaganda com base na quantidade de leitores, ouvintes ou visualizadores. Esse incentivo econômico para a produção de conteúdo digital foi destacado como a principal razão para a proliferação de notícias falsas. Papacharissi (2016), por exemplo, argumenta, "controvérsia gera classificações e, infelizmente, controvérsias são geradas em torno dos fatos".

Essa cadeia argumentativa foi, por exemplo, apresentada no trabalho conduzido pelo Buzzfeed News, mostrando que as reportagens falsas geraram mais engajamento em mídias sociais durante a eleição americana que as notícias reais (Silverman, 2016a). Uma explicação econômica relacionada à causa de notícias falsas diz respeito aos custos de produção mais baixos de informações falsas em comparação com notícias reais (Zimdars, 2016).

As consideradas mais relevantes para a propagação de notícias falsas são o Facebook e o Google - plataformas que a Srnicek (2017) categoriza como "plataformas de publicidade" ou que "extraem informações sobre usuários, realizam um trabalho de análise e usam os produtos desse processo para vender espaço publicitário". Isso porque informações falsas e com conteúdo extremo geram maior engajamento no Facebook do que notícias da mídia tradicional. Esta foi a conclusão de um estudo recente do Instituto de Internet da Universidade de Oxford realizada em 2019, mostrando que as postagens que trazem informações falsas e conteúdos extremos têm mais interação dos usuários de redes sociais, principalmente Twitter e Facebook, que as notícias veiculadas pela mídia tradicional.

Nos anos 1990, a internet era celebrada como uma invenção que inauguraria uma nova era da democracia cultural e política, talvez por meio de novas formas de "governança eletrônica" e contribuições diretas de cidadãos-jornalistas. Curran etal. (2012) analisam algumas dessas previsões entusiásticas, que da perspectiva de hoje parecem falso e tão divertido (ou trágico) quanto às previsões da década de 1950 de que a energia nuclear tornaria a eletricidade tão abundante que seria finalmente cedida gratuitamente. Já é realidade o fato de que hoje nos informamos bastante pela Internet, incluindo as redes sociais.

Com o surgimento da "rede participativa" (Jenkins, 2006), o conteúdo gerado pelo usuário tornou-se uma parte cada vez mais importante da cultura digital (Grossman, 2006; Mitchem, 2008). Plataformas digitais podem democratizar a criação e a circulação de notícias, no entanto, ao fazerem isso, reflexões sobre o que é notícia, como ela é feita, compartilhada e lida em contextos online também são levantadas. Como resultado, tem havido pedidos para que os indivíduos adotem uma postura mais informada e crítica em relação às suas fontes. Embora o viés nas notícias não seja novo, as oportunidades trazidas pela democratização, monetização e circulação de "notícias" por meio de plataformas digitais trouxeram essa questão para um ponto crítico, destacado pela surpreendente vitória eleitoral de Trump (Pangrazio, 2018).

0 clickbait, que em português significa "caça-cliques", conforme definido pela English Oxford Living Dictionaries (2017), é o "conteúdo (na internet) cujo principal objetivo é atrair a atenção e incentivar os visitantes a clicar em um link para uma determinada página da web". No entanto, uma vez compartilhados por "amigos" nas plataformas de mídia social, essas notícias falsas adquirem uma legitimidade que explora as relações afetivas entre os usuários e seu preconceito político predeterminado. 
Uma das características mais importantes da internet é a grande quantidade de notícias e informações a que os usuários têm acesso. Embora isso tenha benefícios óbvios, o fluxo constante de informações pode, ao mesmo tempo, trazer dificuldades para os usuários navegarem. Esse 'infoglut', como Andrejevic (2013) denomina, levou à criação de uma matriz de ferramentas digitais, estratégias de mineração de dados e algoritmos que filtram informações para estabelecer uma experiência mais personalizada e simplificada da web para os usuários (Mobasher; Cooley; Srivastava, 2000).

Em 2011, o Facebook introduziu o botão "like" - um plug-in que pode ser incluído em qualquer site. Com o advento desse botão social, todas as páginas da web se tornaram potencialmente "curtidas". Como Gerlitz e Helmond (2013) explicam, isso significa que o Facebook e a rede externa estão cada vez mais interconectados, à medida que as práticas de um espaço afetam o outro, "tornando-as mais abertas e relacionais". De fato, a arquitetura da plataforma do Facebook - incluindo o design da interface e a proliferação de botões sociais na Internet-significa que notícias e informações são facilmente compartilhadas com uma série de atores sociais e comerciais.

De acordo com uma análise de conteúdo do Laboratório de Mídia do Massachusetts Institute of Technology (MIT), as fakes news se disseminam seis vezes mais rápido que notícias verdadeiras nessa plataforma. 0 estudo identificou ainda que as fake news são 70\% mais propensas a serem 'retweetadas' do que fatos verdadeiros. Segundo os experts do MIT, os usuários de "carne e osso" são os que se saem melhor na tarefa de divulgar notícias falaciosas no Twitter. A explicação, segundo os pesquisadores, pode ser bem simples: novidades atraem a atenção humana.

Como Apperley e Parikka (2015, p.5) explicam, as plataformas "não são apenas tecnologias, mas técnicas que sustentam as interações, além de oferecer uma estrutura epistemológica". Especificamente, as redes sociais tendem a ser compostas de pessoas com ideias afins, o que está associado ao fenômeno do viés de confirmação, no qual procuramos ou acreditamos mais prontamente informações que confirmem o que sabemos ou valorizamos (Braucher, 2016).

A influência das notícias falsas, disseminadas pelas redes sociais, e tidas como fonte primária de notícias da sociedade atual, tornou-se um fenômeno que colocou em alerta os meios de comunicação e os poderes públicos, convertendo-se em motivo de preocupação mundial. As notícias falsas surgiram contra um pano de fundo de mudanças contínuas na sociedade, como a crescente desconfiança das instituições públicas e dos meios de comunicação (Nicolaou; Giles, 2017), bem como o declínio dos jornalistas profissionais (Clark; Marchi, 2017).

Pauner Chulvi (2018) aborda o apelo que instituições comunitárias lançaram às grandes empresas de tecnologia para impedir a disseminação de informações fraudulentas que inundam a rede e reivindicaram um compromisso semelhante ao seguido na luta contra a propagação de mensagens de ódio por meio das redes sociais.

Apesar disso, existem pressões de governos, teóricos e ativistas para demarcar regulamentações quanto ao modo de ação dos algoritmos e ao fato de como eles podem chegar a influenciar tomadas de decisões ou consolidar tendências entre os usuários (Dornelas, 2018). Danaher (2016) e O'Neil (2016) são alguns dos críticos à opacidade dos códigos informacionais. Os autores tentam alertar para o fato de que estamos vivendo em uma verdadeira "algocracia": um cenário no qual uma infinidade de dados produzidos em massa é coletada, armazenada, rearranjada por códigos de programação, acabando, em algum grau, organizando nossas vidas e o que vemos na Internet.

No artigo Beyond misinformation: understanding and coping with the "post-truth" era, os autores sugerem que as respostas a esse mal-estar envolvam soluções tecnológicas que incorporem princípios psicológicos, uma abordagem interdisciplinar descrita como "tecnocognição" como forma de combater a desinformação em um mundo pós-verdade - uma tecnologia baseada na psicologia e nas ciências cognitivas para atenuar o impacto das fake news. Argumentam ainda que, para ser eficaz, a pesquisa científica sobre desinformação deve ser considerada dentro de um contexto político, tecnológico e social mais amplo. 
A tecnocognição usa as descobertas da ciência cognitiva para informar o projeto de arquiteturas de informação que estimulam a disseminação de informações de alta qualidade e que desencoraja a disseminação de desinformação. Os pesquisadores ainda completam que a desinformação não é, portanto, apenas sobre ser mal informada. É também sobre o bem-estar intelectual geral de uma sociedade.

De acordo com Stephan Lewandowsky, Ultrich Ecker e John Cook (2017).

0 mundo pós-verdade surgiu como resultado de megatendências sociais, como o declínio do capital social, a crescente desigualdade econômica, o aumento da polarização, a diminuição da confiança na ciência e um cenário de mídia cada vez mais fracionado.

Os mesmos autores ainda comentam que a ideia da tecnocognição é que devemos usar o que sabemos sobre psicologia para projetar a tecnologia de uma maneira que minimize o impacto da desinformação. Um exemplo vívido desse discurso pode ser encontrado em um artigo do The New Yorker, argumentando que a única solução a longo prazo para "notícias falsas" é aumentar os fundos para a mídia de serviço público, ou seja, a remoção de incentivos capitalistas (Lemann, 2016).

As autoridades políticas no mundo também têm demonstrado preocupação com relação à contenção da dissipação das notícias falsas pelo mundo. Em 23 de dezembro de 2016, o presidente americano Barack Obama assinou a Portman-Murphy Countering Disinformation and Propaganda Act, conhecida como Lei de Combate à Propaganda e Desinformação, que supostamente permitiria que os Estados Unidos combatessem com mais eficácia a propaganda e a desinformação estrangeira, e como forma de encorajar mais esforços de financiamento a entidades não governamentais para ajudar seus aliados neste empreendimento (Herman, 2017).

Na contramão de algumas plataformas e ferramentas tecnológicas e de lutas governamentais para o decreto de regulamentações mais rigorosas para impelir as fake news, a inteligência artificial (conhecida pela sigla IA) avança associada às notícias falsas. "Deepfakes" (falsificações profundas) é o termo que está sendo usado para designar essa simbiose, cujo estrago potencial, alertam especialistas, é arrasador. 0 lançamento de softwares por empresas de tecnologia que permitem a manipulação de vídeos, textos, áudios e criação de imagens computacionais insólitas, como um verdadeiro photoshop.

Os vídeos deepfake são perigosos e podem ter o potencial de minar a verdade, confundir os espectadores e falsificar a realidade com precisão. Com o advento das redes sociais, a proliferação de tal conteúdo pode ser imparável e pode potencialmente exacerbar os problemas relacionados às teorias de desinformação e conspiração. Em alguns exemplos iniciais de deepfakes, um grande número de famosos líderes políticos, atrizes, comediantes e artistas tiveram seus rostos roubados e transformados em vídeos pornográficos. [...] É crucial ter técnicas para detectar e combater conteúdos digitais profundos que podem incluir vídeos falsos, imagens, pinturas, áudios e assim por diante. Atingir esse propósito não será difícil se houver uma maneira confiável, segura e confiável de rastrear a história do conteúdo digital. (Hasan; Salah, 2019, p.2, tradução nossa)

\section{COMUNICAÇÃO E TECNOLOGIA COMO CONTRIBUIÇÃO À SOCIEDADE}

Se o conteúdo falso está sendo aprimorado pela Inteligência Artificial e seus meios de propagação evoluem, a questão é saber como conter essa avalanche. As empresas do setor de tecnologia e computação afirmam que não param de investir no desenvolvimento de barreiras contra essa verdadeira indústria digital. As ferramentas utilizadas envolvem desde sistemas computacionais como o aumento do efetivo humano nas áreas de segurança. Mas além do aspecto lógico e programático que envolve o tema, há uma forte base ética e cultural que precisa recorrentemente ser debatida. Não apenas barreiras tecnológicas, mas também barreiras encabeçadas pelo monitoramento da sociedade ganham representatividade e dão novos contornos e essa batalha. 
Para Raquel Recuero (2016), a saída para amenizar o efeito das fake news e dos fake writers começa pelos próprios usuários das redes sociais (os fake readers), peças-chave na tarefa de reduzir o alcance das notícias falsas. Quem usa redes sociais, como Facebook ou Twitter, ou se comunica com aplicativos como WhatsApp, precisa compreender que é preciso buscar notícias de fontes conhecidas e com compromisso com a verdade.

Segundo a pesquisadora de redes sociais, é necessário educar as pessoas para que busquem fontes oficiais e curadores compromissados com a ética e a verdade, bem como também é preciso um trabalho com mais qualidade de quem seria 0 principal responsável pela circulação de informações verdadeiras na sociedade: a imprensa.

Se há um exército de robôs e ciborgues construindo um universo paralelo, cabe à comunicação e ao conjunto de seus profissionais trabalhar para esclarecer esse movimento altamente danoso à sociedade. Com ações de disseminação de mentiras, discursos de ódio e teorias negacionistas, a sociedade caminha contra o desenvolvimento e a democracia. Organizações, pesquisadores e profissionais devem trabalhar para levar educação digital e comunicacional a todos, de modo a gerar naturalmente 0 caráter do debate e da crítica.

\section{REFERÊNCIAS}

ADAMI, Elisabetta. The rhetoric of the implicit and the politics of representation in the age of copy-and-paste. Learning, Media and Technology, Abingdon, v.37, n.2, p.131-144, 2012.

ANGELUCI, Alan; SOARES, Silvana; FREITAS, Renata. Phubbing: a comunicação em sala de aula sob a influência dos dispositivos móveis. In: ANGELUCI, Alan etal. (org.). Arte e narrativas emergentes. Aveiro: Ria Editorial, 2019. p.313-333.

APPERLEY, Thomas; PARIKKA, Jussi. Platform studies' epistemic threshold. Games and Culture, Thousand Oaks, v.13, n.4, p.349-369, 2018.

BALDESSAR, Maria José; ZANDOMÊNICO, Regina. As redes sociais como propulsoras do nowism: implicações no jornalismo e na comunicação institucional. In: BUSARELLO, Raul Inácio; ULBRICH, Vania. (org.). Práticas e geração de conhecimento frente às novas mídias. São Paulo: Pimenta Cultural, 2014. p.95-108.

BRAUCHER, D. Fake news: why we fall for it. Psychology Today. Disponível em: https://www.psychologytoday.com/us/blog/ contemporary-psychoanalysis-in-action/201612/fake-news-why-we-fall-it. Acesso em: 2 nov. 2018.

CASTELLS, Manuel. O poder da comunicação. Rio de Janeiro: Paz e Terra, 2015.

CLARK, Lynn Schofield; MARCHI, Regina. Young people and the future of news. Cambridge: Cambridge University Press, 2017.

CURRAN, James; FENTON, Natalie; FREEDMAN, Des. Misunderstanding the internet. Abingdon: Routledge, 2012.

DANAHER, John etal. Algorithmic governance: developing a research agenda through the power of collective intelligence. Big Data \& Society. Disponível em: https://journals.sagepub.com/doi/full/10.1177/2053951717726554. Acesso em: 02 nov. 2018.

DILLET, Benoît. What is Poststructuralism?. Political Studies Review, Disponível em: https://journals.sagepub.com/ doi/10.1177/1478929917712931. Acesso em: 28 jan. 2019 
FLORIDI, Luciano. Is semantic information meaningful data?. Philosophy and Phenomenological Research, Providence, v. 70, n. 2, 2005. Disponível em: http://uhra.herts.ac.uk/bitstream/handle/2299/1825/901828.pdf?sequence=1. Acesso em: 15 mar. 2019.

GROSSMAN, Lev. You - yes, you - are TIME's person of the year. Time Magazine, Hanover, 2006. Disponível em: http://content.time.com/time/magazine/article/0,9171,1570810,00.html. Acesso em: 19 set. 2018.

HASAN, Haya; SALAH, Khaled. Combating deepfake videos using blockchain and smart contracts. IEEE Acess, New York, v.7, p.41596-41606, 2019.

HERMAN, Edward. Fake news on Russia and other oficial enemies. Monthly Review-an Independent Socialist Magazine, New York, v. 69, p. 98-111, 2017

JENKINS, Henry. Confronting the challenges of participatory culture: media education for the 21st century. Cambridge, MA: The MIT Press, 2006.

KOUTRA, Danai; BENNETT, Paul; HORVITZ, Eric. Events and controversies: influences of a shocking news event on information seeking, International World Wide Web Conferences Steering Committee, Florence, n.11, p.614-624, 2014.

LEMANN, Nicholas. Solving the problem of fake news. 2016. The New Yorker. Disponível em: http://www.newyorker.com/news/ news-desk/solving-theproblem-of-fake-news. Acesso em: 12 dez. 2018.

LEWANDOWSKY, Stephan; ECKER, Ullrich K. H.; COOK, John. Beyond misinformation: understanding and coping with the "post-truth" era. Journal of Applied Research in Memory and Cognition, v.6, n.4, p.353-369, 2017.

MARLET, Ramon; BATISTA, Leandro L. Recepção transmidiática: um olhar inicial sobre storytelling e memória narrativa a partir da série Star Wars. In: BUSARELLO, Raul Inácio. Práticas e geração de conhecimento frente às novas mídias. Editora: Pimenta Cultura, 2014. p. 59-76.

MITCHEM, Matthew. Video social: complex parasitical media. In: LOVINK, Geert; NIEDERER, Sabine (org.). Video Vortex Reader. responses to YouTube. Amsterdam: Institute of Network Cultures, 2008. p. 273-282.

MOBASHER, Bamshad; COOLEY, Robert; SRIVASTAVA, Jaideep. Automatic personalization based on web usage mining. Communications of the ACM, New York, v.43, n.8, p.142-151, 2000. Disponível em: http://dl.acm.org/citation.cfm?id=345169. Acesso em: 20 nov. 2019.

NAISH, John. Warning: brain overload. The Times: London, 2009.

NICOLAOU, Anna.; GILES, Chris. Public trust in media at all time low, research shows. Financial Times. Disponível em: https:// www.ft.com/content/fa332f58-d9bf-11e6-944b-e7eb37a6aa8e. Acesso em: 10 set. 2018.

NIKOLOV, Dimitar etal. Measuring online social bubbles. Peer J Computer Science, London, v.1, n.38, p.1-14, 2015.

O'NEIL, Cathy. How can we stop algorithms telling lies?. The Guardian. 2017. Disponível em: https://www.theguardian.com/ technology/2017/jul/16/how-can-we-stop-algorithms -telling-lies. Acesso em: 2 fev. 2019. 
PACCAGNELLA, Luciano. Post-truth: hoaxes, misinformation, trust and reputation in the network society. International Journal Of E-politics, Hershey, v.9, n.2, p.1-13, 2018.

PANGRAZI, Luci. What's new about 'fake news'? Critical digital literacies in an era of fake news, post-truth and clickbait. Revista Páginas de Educación, Montevideo, v.11, n.1, p.6-22, 2018.

PARISIER, Eli. The filter buble: what the internet is hiding from you. Old Saybrook: Tantor Audio, 2011.

PAUNER CHUVI, Cristina. Fake news and freedom of expression and information: the control of information contents on the network. Madri, v.41, p.297-318, 2018.

RECUERO, Raquel. Redes sociais na internet. Porto Alegre: Sulina, 2009

SANTAELLA, Lucia. A Pós-verdade é verdadeira ou falsa? São Paulo: Estação das Letras e Cores, 2018.

SILVERMAN, Craig etal. Hyperpartisan Facebook pages are publishing false and misleading information at an alarming rate. Buzzfeed News. 2016. Disponível em: https://www.buzzfeed.com/craigsilverman/partisan-fb-pages-analysis?utm_ term=.an8 2QeMMJe\#.wb8jdLOOqL. Acesso em: 29 nov. 2018.

SILVERSTONE, Roger. Por que estudar a mídia? 3. ed. São Paulo: Edições Loyola, 2011.

SODRÉ, Muniz. Antropológica do espelho: uma teoria da comunicação linear e em rede. Petrópolis: Vozes, 2002.

TAMBUSCIO, Marcella etal. Fact-checking effect on viral hoaxes: a model of misinformation spread in social networks. Proceedings of the 24th international conference on World Wide Web, New York, p. 977-982, 2015.

TOFFLER, Alvin. O choque do futuro. 2. ed. São Paulo: Record, 1973.

VINER, Katharine. How technology disrupted the truth. The Guardian. 2016. Disponível em: https://www.theguardian.com/media/ 2016/jul/12/how-technology-disrupted-the-truth. Acesso em: 1 mar. 2019.

ZIMDARS, Melissa. My "fake news list" went viral. but made-up stories are only part of the problem. The Washington Post. Disponível em: https://www.washingtonpost.com/posteverything/wp/2016/11/18/my-fake-news-list-w ent-viral-butmade-upstories-are-only-part-of-the-problem/. Acesso em: 10 out. 2018.

Artigo recebido em 13.10.2020 e aprovado em 13.10.2020. 